\title{
Procedural sedation for intra-articular corticosteroid injections in juvenile idiopathic arthritis (JIA) should be a standard of care: reply
}

\author{
Rocío Casado • Javier Lumbreras • Jaime de Inocencio
}

Received: 29 November 2013 / Accepted: 11 December 2013 / Published online: 27 December 2013

(C) Springer-Verlag Berlin Heidelberg 2013

We appreciate the interest and comments of Dr Pastore et al. and value the opportunity to respond to their letter to the editor.

The objective of our study was to analyze the views of parents and patients regarding a common procedure in rheumatology and not to compare the different sedation techniques available for it.

We congratulate the authors for their experience in the use of non-anesthesiologists administered propofol (NAAP), a protocol we do not use because, in our center, the procedures which associate pain are performed at the Pediatric Pain Unit staffed by pediatric anesthesiologists. In regards to the sedation protocol used, we did not address the advantages and disadvantages of each technique but just described the one we used.

Finally, our aim was to show how the perception of the pain associated with the arthrocentesis and the risks associated with sedation conditioned the choices of patients and parents, beyond objective considerations on the safety or efficacy of any sedation technique.

R. Casado ( $\bowtie)$

Centro de Salud Santa Ponsa, Calvià, Baleares, Spain

e-mail: rocapi81@hotmail.com

J. Lumbreras

Pediatric Nephrology Unit, University Hospital Son Espases, Palma

de Mallorca, Baleares, Spain

J. de Inocencio

Pediatric Rheumatology Unit, University Hospital Doce de Octubre,

Madrid, Spain 